\title{
Different training status may alter the continuous blood glucose kinetics in self-paced endurance running
}

\author{
YOSHIO SUZUKI $^{1}$, TOMOMI SHIMIZU ${ }^{2}$, MAKOTO OTA $^{3}$, RYUZO HIRATA $^{4,9}$, KENJI SATO $^{5,10}$, \\ YOSHIFUMI TAMURA ${ }^{6}$, AKIO IMANISHI ${ }^{7}$, MASAYUKI WATANABE $^{8}$ and KEISHOKU SAKURABA ${ }^{1}$ \\ ${ }^{1}$ Graduate School of Health and Sports Science, Juntendo University, Inzai, Chiba 270-1695; \\ ${ }^{2}$ Faculty of Biomedical Engineering, Toin University of Yokohama, Aoba, Yokohama, Kanagawa 225-8503; \\ ${ }^{3}$ Graduate School of Sports and Health Science, Daito Bunka University, Matsuyama, Saitama 355-8501; \\ ${ }^{4}$ Katsushika Medical Center, Jikei University, Tokyo 125-8506; ${ }^{5}$ Division of Applied Sciences, Kyoto Prefectural University, \\ Shimogamo, Kyoto 606-8522; ${ }^{6}$ Department of Medicine, Metabolism and Endocrinology, School of \\ Medicine, Juntendo University, Tokyo 113-8421; ${ }^{7}$ Faculty of Sports and Health Science, Daito Bunka \\ University, Matsuyama, Saitama 355-8501; ${ }^{8}$ Tokyo Gakugei University, Tokyo 184-0015, Japan
}

Received August 23, 2014; Accepted May 29, 2015

DOI: $10.3892 / \mathrm{etm} .2015 .2587$

\begin{abstract}
The main purpose of the systemic energy metabolism is to provide a source of energy, mainly glucose, for the brain; therefore, blood glucose levels would be expected to correlate with exercise performance. The individual training status may also affect the blood glucose levels. The aim of the present study was to assess the association between blood glucose levels and running velocity during prolonged running in athletes with different training statuses. Two female college athletes, a triathlete and a tennis player, ran a course that was $247.4 \mathrm{~m}$ in circumference for $5 \mathrm{~h}$ while wearing a continuous glucose monitoring system. Blood was obtained at time-points of $-1,1,3$ and $5 \mathrm{~h}$. The athletes had free access to food and fluids throughout the run. The athletes ran at almost the same pace without a sudden decrease in pace. The blood glucose levels increased and remained high in the triathlete, whereas the tennis player remained hypoglycemic throughout the run. Carbohydrate ingestion did not affect the blood glucose levels. The magnitude of hormonal changes, e.g. insulin, adrenaline and cortisol, was greater in the tennis player. The blood glucose concentration did not correlate with the running velocity or
\end{abstract}

Correspondence to: Dr Yoshio Suzuki, Graduate School of Health and Sports Science, Juntendo University, 1-1 Hiraga-gakuendai, Inzai, Chiba 270-1695, Japan

E-mail: yssuzuki@juntendo.ac.jp

Present addresses: ${ }^{9}$ Daisan Hospital, Jikei University, Tokyo 201-8601; ${ }^{10}$ Division of Applied Biosciences, Graduate School of Agriculture, Kyoto University, Kitashirakawa, Kyoto 606-8502, Japan

Key words: glucose, continuous glucose monitoring system, prolonged exercise, running the carbohydrate ingestion; however, a discrepancy in blood glucose transition was observed between the triathlete and the tennis player, indicating a possible association between the adaptation to endurance exercise and the blood glucose kinetics during prolonged running.

\section{Introduction}

The major purpose of the systemic energy metabolism is to provide an energy source for the brain. The brain mainly utilizes glucose and, if available, ketone bodies and lactate (1). During prolonged exercise, muscles use intramuscular glycogen and triacylglycerol (TG), as well as circulating fuel sources. The muscle takes up glucose, fatty acids, ketone bodies and potentially TG from the circulation $(2,3)$. Carbohydrate is the primary preferential substrate for muscle, whereas the priority can be changed to lipid under exercise (4).

The pace of marathon runners can sometimes abruptly decrease after $\sim 30 \mathrm{~km}$, as the runners are struck by a sudden feeling of exhaustion. This is called 'hitting the wall' and it is explained as the depletion of intramuscular glycogen stores and the absence of a suitable energy source in the circulation (5). Sengoku et al (6) described an individual who ran a $100-\mathrm{km}$ marathon while wearing a continuous glucose monitoring system (CGMS). The runner maintained a constant pace of $11-12 \mathrm{~km} / \mathrm{h}$ for $60 \mathrm{~km}$ but dropped the pace to $6 \mathrm{~km} / \mathrm{h}$ for the next $30 \mathrm{~km}$. The kinetics of the blood glucose concentration were synchronized with running velocity, being $\sim 5.5 \mathrm{mM}$ up to $60 \mathrm{~km}$ and $\sim 3.3 \mathrm{mM}$ during the next $30 \mathrm{~km}(6)$. A recent report by the same author (7), however, described two cases showing discordance between blood glucose and running velocity.

Plasma glucose contributes $\sim 10 \%$ of the energy expenditure during exercise with intensity ranging between 25 and $85 \%$ of maximum oxygen uptake $\left(\mathrm{VO}_{2} \max \right)(8)$; however, the difference in the adaptation to endurance exercise could affect muscle glucose consumption. Coggan et al (9) reported that 12 weeks of training lowered plasma glucose utilization 
from 21 to $15 \%$ of total energy expenditure during $90-120 \mathrm{~min}$ of exercise. Another study (10) found that trained athletes oxidized only $5 \%$ of the total blood glucose as an energy source during exercise at $65 \% \mathrm{VO}_{2}$ max intensity for $60 \mathrm{~min}$, whereas untrained individuals required $23 \%$ of the blood glucose under the same conditions.

The association among blood glucose levels, running performance and training status has, therefore, not been clarified. In addition, the continuous glucose transition during prolonged running with the kinetics of hematological and biochemical indices in healthy individuals has, to the best of our knowledge, not been reported. Therefore, in the present study, two athletes with different training statuses were monitored running for $5 \mathrm{~h}$ wearing a CGMS.

\section{Materials and methods}

Subjects. Two healthy female college athletes participated in the present study. Athlete A was a triathlete (age, 21 years; height, $166 \mathrm{~cm}$; weight, $62 \mathrm{~kg}$; $\left.\mathrm{VO}_{2} \max , 59.6 \mathrm{ml} / \mathrm{kg} / \mathrm{min}\right)$ and athlete $\mathrm{B}$ was a tennis player (age, 21 years; height, $169 \mathrm{~cm}$; weight, $58 \mathrm{~kg}$; $\left.\mathrm{VO}_{2} \max , 42.1 \mathrm{ml} / \mathrm{kg} / \mathrm{min}\right)$. Both received detailed information about the purpose, methods, expected results and ethical considerations, including possible adverse effects, relevant to the study, and both athletes provided written informed consent to participate in the study. The athletes ate dinner as usual, slept for $\geq 5 \mathrm{~h}$ on the day prior to the experiment and then ate breakfast and arrived at the site of the experiment by 09:30 the following morning.

Study design. The athletes participated for $6 \mathrm{~h}$ in the First Japan 24 h Indoor Ultramarathon Race (Tokyo, Japan) on December 17, 2011, which comprised running around a circular course with a circumference of $247.4 \mathrm{~m}$. The athletes ran from 11:00 to 16:00 at their own pace, aiming to maintain their heart rates between 140 and $180 \mathrm{bpm}$ with reference to an RS800CX heart-rate monitor (Polar, Kempele, Finland); however heart rate data were not available for athlete B as the start button was not pressed. Food and fluids were freely provided by the race organizer throughout the event. The energy and carbohydrate intake was calculated using a food composition database (11), which gave the following results: Subject A, 940.2 kcal (including $88.1 \mathrm{~g}$ carbohydrate); and subject B, 1,006.1 kcal (including $137.2 \mathrm{~g}$ carbohydrate) (Table I). Athletes A and B ran 43.048 and $34.141 \mathrm{~km}$, respectively. The running velocity was calculated by lap time (Fig. 1). The estimated oxygen uptake at the average velocity of the initial $57 \mathrm{~min}, 10.3 \mathrm{~km} / \mathrm{h}$, was $34.8 \mathrm{ml} / \mathrm{kg} / \mathrm{min}$ according to the table provided by Cooper (12). Thus, the exercise intensity for the initial $1 \mathrm{~h}$ was estimated to be 58.4 and $82.7 \% \mathrm{VO}_{2}$ max for athletes $\mathrm{A}$ and $\mathrm{B}$, respectively. During the race, the athletes wore a Minimed CGMS-Gold ${ }^{\circledR}$ (Medtronic, Tokyo, Japan) with the glucose sensor positioned subcutaneously $\sim 20 \mathrm{~cm}$ lateral to the hilum. Blood was collected $1 \mathrm{~h}$ before and 1,3 and $5 \mathrm{~h}$ after starting the race. The Ethics Committee of Juntendo University (Inzai, Chiba) approved the study protocol (Jundai SuRin no. 23-24).

Analysis. Serum albumin, insulin, glucagon, catecholamine, adrenocorticotropic hormone (ACTH), arginine vasopressin

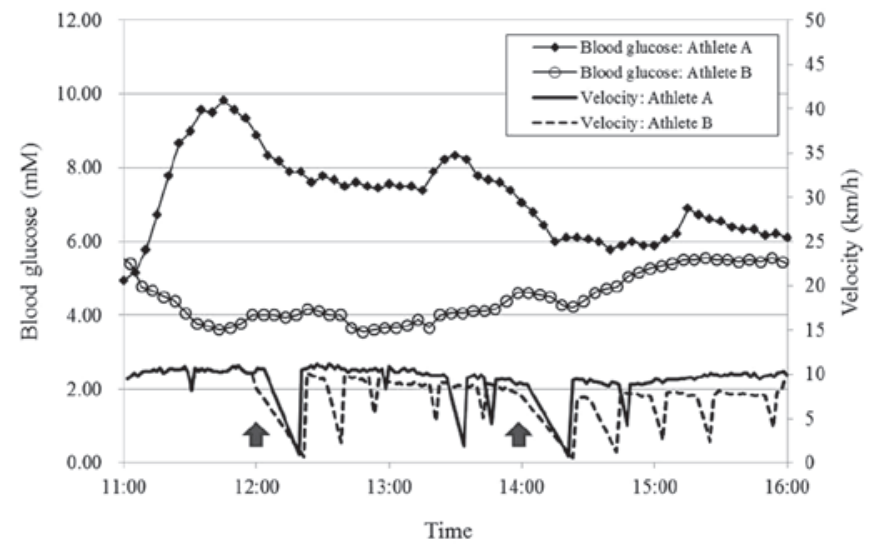

Figure 1. Blood glucose kinetics and running velocity during a 5-h run. Running velocity was calculated every lap (247.4 m). Arrows indicate the short rest for blood collection.

(AVP), cortisol, TG, non-esterified fatty acid (NEFA), acetoacetic acid and 3-hydroxybutyric acid (3-HB) were analyzed at an authorized clinical laboratory (SRL, Inc., Tokyo, Japan) using the methods and reagents described below. Albumin was assayed by bromocresol purple dye-binding assay using Pureauto ${ }^{\circledR} S$ ALB reagent (Sekisui Medical, Tokyo, Japan). Insulin, ACTH, cortisol and testosterone were assayed by electrochemiluminescence immunoassay using Lumipulse ${ }^{\circledR}$ Presto ${ }^{\circledR}$ for insulin (Fujirebio, Tokyo, Japan) and ECLusys reagents for ACTH, cortisol and testosterone (Roche Diagnostics, Mannheim, Germany). Glucagon and AVP were analyzed by double-antibody radioimmunoassay (RIA) using the Millipore glucagon RIA (Merck Millipore, Darmstadt, Germany) and AVP RIA Mitsubishi (Mitsubishi Chemical Corp., Tokyo, Japan) kits, respectively. Catecholamines (adrenaline, noradrenaline and dopamine) were measured by high-performance liquid chromatography. TG and NEFAs were analyzed using PureAutoS TG-N reagent (Sekisui Medical) and an NEFA-SS Eiken kit (Eiken Chemical, Tokyo, Japan), respectively. Total ketone bodies and 3-HB were measured by the Kainos ${ }^{\circledR}$ reagents for total ketone bodies and 3-HB (Kainos Laboratories, Inc., Tokyo, Japan), respectively. The acetoacetic acid level was calculated as the difference between the measurements for total ketone bodies and 3-HB. Plasma amino acids were determined according to the method of Bidlingmeyer et al (13) with slight modifications (14).

\section{Results}

Blood glucose. Blood glucose levels in athlete A increased to $\sim 10 \mathrm{mM}$ soon into the run and then gradually decreased, but remained $>5.5 \mathrm{mM}$ throughout the run. By contrast, the blood glucose levels in athlete $\mathrm{B}$ fell to $3.6 \mathrm{mM}$ during the run and then gradually increased, although without reaching the pre-run level (Fig. 1). Athlete B ingested more carbohydrates than athlete A during the run (Table I). The timing and amount of the carbohydrate did not directly reflect the blood glucose level (Fig. 1).

Biochemical parameters. Plasma glucagon, ACTH, AVP, adrenaline, noradrenaline and dopamine levels increased 
Table I. Energy and carbohydrate intake during the 5-h run.

\begin{tabular}{|c|c|c|c|c|}
\hline \multirow[b]{2}{*}{ Time } & \multicolumn{2}{|c|}{ Athlete A } & \multicolumn{2}{|c|}{ Athlete B } \\
\hline & Energy (kcal) & Carbohydrate (g) & Energy (kcal) & Carbohydrate (g) \\
\hline $11: 00-12: 00$ & 19.0 & 4.7 & - & - \\
\hline $12: 00-13: 00$ & 195.1 & 24.8 & 158.6 & 25.6 \\
\hline $13: 00-14: 00$ & 290.0 & 46.5 & 175.9 & 28.8 \\
\hline $14: 00-15: 00$ & 436.1 & 12.1 & 454.6 & 36.9 \\
\hline $15: 00-16: 00$ & - & - & 217.0 & 45.9 \\
\hline Total & 940.2 & 88.1 & $1,006.1$ & 137.2 \\
\hline
\end{tabular}

Table II. Biochemical parameters.

\begin{tabular}{|c|c|c|c|c|c|c|c|c|}
\hline \multirow[b]{2}{*}{ Parameter } & \multicolumn{4}{|c|}{ Athlete A } & \multicolumn{4}{|c|}{ Athlete B } \\
\hline & Pre & $1 \mathrm{~h}$ & $3 \mathrm{~h}$ & $5 \mathrm{~h}$ & Pre & $1 \mathrm{~h}$ & $3 \mathrm{~h}$ & $5 \mathrm{~h}$ \\
\hline Albumin (g/dl) & 5.4 & 5.0 & 5.1 & 5.1 & 5.1 & 5.5 & 5.3 & 5.3 \\
\hline Insulin $(\mu \mathrm{IU} / \mathrm{ml})$ & 5.64 & 11.6 & 3.85 & 9.62 & 42.9 & 10.7 & 4.49 & 9.95 \\
\hline Glucagon (pg/ml) & 59 & 63 & 87 & 66 & 78 & 114 & 164 & 123 \\
\hline ACTH (pg/ml) & 15.2 & 22.5 & 31.9 & 43.2 & 36.4 & 68.8 & 68.4 & 43.9 \\
\hline Cortisol $(\mu \mathrm{g} / \mathrm{dl})$ & 10.1 & 8.7 & 12.3 & 17 & 10.6 & 20.6 & 25.2 & 17.8 \\
\hline Vasopressin (pg/ml) & 1.2 & 1.4 & 1.7 & 3.1 & 1.5 & 1.8 & 3.7 & 2.1 \\
\hline \multicolumn{9}{|l|}{ Catecholamines } \\
\hline Adrenaline (pg/ml) & 29 & 50 & 81 & 59 & 16 & 56 & 236 & 125 \\
\hline Noradrenaline (pg/ml) & 478 & 595 & 753 & 756 & 422 & 782 & 1,053 & 978 \\
\hline Dopamine (pg/ml) & 5 & 19 & 20 & 23 & 15 & 34 & 69 & 102 \\
\hline Triacylglycerol & 80 & 63 & 54 & 69 & 94 & 58 & 60 & 50 \\
\hline $\operatorname{NEFA}(\mu \mathrm{Eq} / 1)$ & 171 & 726 & 813 & 1,589 & 82 & 618 & 1,579 & 1,411 \\
\hline \multicolumn{9}{|l|}{ Ketone bodies } \\
\hline Acetoacetic acid $(\mu \mathrm{mol} / \mathrm{l})$ & 10 & 21 & 31 & 55 & 10 & 21 & 72 & 69 \\
\hline 3-HB $(\mu \mathrm{mol} / \mathrm{l})$ & 12 & 27 & 40 & 86 & 11 & 44 & 84 & 102 \\
\hline Total ketone bodies ${ }^{\mathrm{a}}(\mu \mathrm{mol} / \mathrm{l})$ & 22 & 48 & 71 & 141 & 21 & 65 & 156 & 171 \\
\hline
\end{tabular}

${ }^{\text {aS }}$ um of acetoacetic acid and 3-HB. ACTH, adrenocorticotropic hormone; NEFA, non-esterified fatty acid; 3-HB, hydroxybutyric acid.

during the run in both athletes, although their magnitude and kinetics differed between the athletes (Table II). Adrenaline in athlete A rose by 2.9 -fold (from 29 to $81 \mathrm{pg} / \mathrm{ml}$ ), and by 14.8 -fold (from 16 to $236 \mathrm{pg} / \mathrm{ml}$ ) in athlete B. Noradrenaline increased by 1.6 -fold (from 478 to $756 \mathrm{pg} / \mathrm{ml}$ ) in athlete A and 2.5 -fold (from 422 to $1,053 \mathrm{pg} / \mathrm{ml}$ ) in athlete B. ACTH reached a peak at $1 \mathrm{~h}$ in athlete $\mathrm{B}$, and at $5 \mathrm{~h}$ in athlete $\mathrm{A}$. AVP reached a peak at $5 \mathrm{~h}$ in athlete $\mathrm{A}$, and at $3 \mathrm{~h}$ in athlete B. In addition, it was found that the total plasma amino acids during the first $3 \mathrm{~h}$ increased in athlete $\mathrm{A}$ but decreased in athlete $B$; thereafter, the levels decreased in athlete $A$ and increased in athlete B. This inconsistency was mainly due to differences in levels of non-essential amino acids (NEAAs) during the first $3 \mathrm{~h}$ and in essential amino acids (EAAs) over the next $2 \mathrm{~h}$ (Table III).

\section{Discussion}

The two athletes ran $>30 \mathrm{~km}$, at the same pace in the initial $1 \mathrm{~h}$; however, the blood glucose levels were notably different between them. The blood glucose concentration of athlete $\mathrm{B}$ decreased to a minimum of $3.6 \mathrm{mM}$ at $12: 48$ and then recovered gradually. By contrast, the running velocity of athlete B was maintained at $\sim 10 \mathrm{~km} / \mathrm{h}$ until the first break for blood collection at noon, and then gradually decreased following the restart with periodical valleys (Fig. 1). In athlete A, however, the blood glucose levels increased from the start of the run to $9.8 \mathrm{mM}$ by $11: 45$, and then gradually decreased, although they remained higher than the pre-run blood glucose level. These kinetics did not reflect the running velocities of the two athletes. 
Table III. Plasma amino acid concentrations in the athletes.

\begin{tabular}{|c|c|c|c|c|c|c|c|c|}
\hline \multirow[b]{2}{*}{ Amino acid } & \multicolumn{4}{|c|}{ Athlete A } & \multicolumn{4}{|c|}{ Athlete B } \\
\hline & Pre & $1 \mathrm{~h}$ & $3 \mathrm{~h}$ & $5 \mathrm{~h}$ & Pre & $1 \mathrm{~h}$ & $3 \mathrm{~h}$ & $5 \mathrm{~h}$ \\
\hline Aspartic acid $(\mu \mathrm{mol} / \mathrm{l})$ & 15.1 & 11.3 & 11.8 & 11.0 & 15.1 & 11.5 & 9.8 & 9.9 \\
\hline Glutamic acid $(\mu \mathrm{mol} / \mathrm{l})$ & 36.6 & 37.7 & 39.6 & 39.4 & 33.8 & 27.9 & 35.4 & 33.1 \\
\hline Asparagine $(\mu \mathrm{mol} / \mathrm{l})$ & 41.1 & 50.1 & 47.7 & 48.3 & 57.9 & 41.4 & 33.9 & 35.4 \\
\hline Serine $(\mu \mathrm{mol} / \mathrm{l})$ & 93.8 & 115.6 & 112.4 & 97.9 & 124.4 & 96.5 & 86.2 & 83.4 \\
\hline Glutamine $(\mu \mathrm{mol} / \mathrm{l})$ & 475.8 & 575.2 & 626.2 & 662.7 & 614.7 & 571.8 & 516.0 & 525.1 \\
\hline Glycine $(\mu \mathrm{mol} / \mathrm{l})$ & 242.6 & 267.4 & 246.8 & 235.3 & 275.5 & 212.6 & 179.1 & 154.6 \\
\hline Histidine $(\mu \mathrm{mol} / \mathrm{l})$ & 64.0 & 74.0 & 78.7 & 80.0 & 80.5 & 71.0 & 58.2 & 63.4 \\
\hline Arginine $(\mu \mathrm{mol} / \mathrm{l})$ & 78.6 & 92.6 & 92.1 & 96.0 & 88.5 & 77.9 & 68.2 & 74.8 \\
\hline Taurine $(\mu \mathrm{mol} / \mathrm{l})$ & 115.5 & 72.8 & 100.3 & 80.3 & 96.6 & 69.9 & 68.5 & 62.2 \\
\hline Threonine $(\mu \mathrm{mol} / \mathrm{l})$ & 124.4 & 144.7 & 145.4 & 137.5 & 131.7 & 106.7 & 93.5 & 93.3 \\
\hline Alanine $(\mu \mathrm{mol} / 1)$ & 439.3 & 535.3 & 499.9 & 426.3 & 399.7 & 393.2 & 266.3 & 240.2 \\
\hline Proline $(\mu \mathrm{mol} / \mathrm{l})$ & 137.2 & 145.6 & 136.4 & 130.9 & 204.5 & 183.2 & 159.8 & 131.2 \\
\hline Tyrosine $(\mu \mathrm{mol} / \mathrm{l})$ & 79.0 & 102.4 & 122.3 & 123.0 & 80.2 & 90.7 & 98.1 & 96.8 \\
\hline Valine $(\mu \mathrm{mol} / \mathrm{l})$ & 209.5 & 235.4 & 325.3 & 254.1 & 227.9 & 224.4 & 206.2 & 371.6 \\
\hline Methionine $(\mu \mathrm{mol} / \mathrm{l})$ & 20.2 & 29.5 & 32.6 & 25.5 & 26.0 & 33.5 & 24.9 & 19.5 \\
\hline Isoleucine $(\mu \mathrm{mol} / \mathrm{l})$ & 62.3 & 74.3 & 138.5 & 75.8 & 67.9 & 58.9 & 60.2 & 145.3 \\
\hline Leucine $(\mu \mathrm{mol} / \mathrm{l})$ & 109.9 & 134.6 & 254.1 & 142.7 & 116.0 & 126.3 & 111.5 & 281.0 \\
\hline Phenylalanine $(\mu \mathrm{mol} / \mathrm{l})$ & 79.8 & 86.7 & 93.1 & 104.2 & 80.3 & 77.1 & 82.8 & 89.5 \\
\hline Lysine $(\mu \mathrm{mol} / \mathrm{l})$ & 145.2 & 165.2 & 157.1 & 150.5 & 141.7 & 101.0 & 93.2 & 94.4 \\
\hline Gln/Glu & 13.0 & 15.3 & 15.8 & 16.8 & 18.2 & 20.5 & 14.6 & 15.8 \\
\hline $\operatorname{BCAAs}^{\mathrm{a}}(\mu \mathrm{mol} / \mathrm{l})$ & 381.6 & 444.3 & 717.9 & 472.6 & 411.9 & 409.6 & 377.9 & 798.0 \\
\hline EAAs $(\mu \mathrm{mol} / \mathrm{l})$ & 894.2 & $1,046.9$ & $1,347.1$ & $1,093.3$ & 952.2 & 889.5 & 828.6 & $1,254.7$ \\
\hline NEAAs $(\mu \mathrm{mol} / \mathrm{l})$ & $1,560.1$ & $1,830.9$ & $1,813.0$ & $1,747.9$ & $1,814.2$ & $1,616.0$ & $1,354.6$ & $1,287.8$ \\
\hline Total AAs $(\mu \mathrm{mol} / \mathrm{l})$ & $2,454.3$ & $2,877.8$ & $3,160.1$ & $2,841.2$ & $2,766.4$ & $2,505.5$ & $2,183.2$ & $2,542.5$ \\
\hline
\end{tabular}

${ }^{\text {a } V a l i n e ~+~ l e u c i n e ~+~ i s o l e u c i n e . ~ G l n / G l u, ~ g l u t a m i n e / g l u t a m i c ~ a c i d ; ~ B C A A, ~ b r a n c h e d-c h a i n ~ a m i n o ~ a c i d ; ~ E A A, ~ e s s e n t i a l ~ a m i n o ~ a c i d ; ~ N E A A, ~}$ nonessential amino acid.

Carbohydrate intake during the run did not appear to affect the blood glucose concentrations. Athletes A and B ingested 88.1 and $137.2 \mathrm{~g}$ carbohydrate, respectively, but their glucose levels did not simultaneously increase. This was in agreement with the report by Sengoku et al (7).

In athlete $\mathrm{B}$, the blood glucose concentration stopped falling and recovered after $3 \mathrm{~h}$ of running. Simultaneously, the EAA levels increased, with the increase exceeding the decrease in NEAAs to elevate the levels of total amino acids. EAAs cannot be endogenously syntheized and thus the increase should indicate extensive protein breakdown. Ezaki et al (15) reported that the increase in plasma EAAs occurred via hepatic autophagy to maintain blood glucose in starved mice. The same autophagy could be suggested in athlete B.

In athlete $\mathrm{B}$, the insulin concentrations were higher than those in athlete A throughout the experiment. The initial level may have been due to breakfast, since the diet was not controlled or recorded by the first blood collection. This may account for the initial decrease in the blood glucose; however, the insulin-to-glucagon ratio was higher in athlete $A$ than that in athlete B during the running. Thus, the insulin levels alone could not account for the hypoglycemia in athlete B.
The changes in ACTH, cortisol, catecholamines and glucagon appeared to promote glycolysis to release glucose in the circulation, although the effect was not distinctively shown in the blood glucose levels. The magnitude of the change in these hormones was greater in athlete $\mathrm{B}$, which may have been due to the training status: Athlete A, a triathlete, may have been more adapted to endurance running.

It was expected that the blood glucose concentration would correlate with the running velocity and carbohydrate ingestion, but that was not proven. However, a discrepancy in the blood glucose transition was observed between the triathlete and the tennis player, indicating a possible association between the adaptation to endurance exercise and the blood glucose kinetics during prolonged running. Despite this, further study is warranted to clarify the association between training status and glucose kinetics, as the number of subjects studied was limited.

\section{Acknowledgements}

The authors would like to thank Mr. T. Kawana of Juntendo University Urayasu Hospital for his assistance in specimen 
collection. Part of this study was presented at the $67 \mathrm{th}$ Annual Meeting of the Japanese Society of Physical Fitness and Sports Medicine, September 14-16, 2012 in Gifu, Japan. The present study was funded by Juntendo University (grant no. 1508-048).

\section{References}

1. Amiel SA: Organ fuel selection: Brain. Proc Nutr Soc 54: 151-155, 1995.

2. Kiens B: Skeletal muscle lipid metabolism in exercise and insulin resistance. Physiol Rev 86: 205-243, 2006.

3. Henriksson J: Muscle fuel selection: Effect of exercise and training. Proc Nutr Soc 54: 125-138, 1995.

4. Lindholm A: What determines fuel selection in relation to exercise? Proc Nutr Soc 54: 275-282, 1995.

5. Newsholm E, Leech T and Duester G (eds): Keep on Running: The Science of Training and Performance. John Wiley \& Sons, Chichester, 1994.

6. Sengoku Y, Nakamura K, Ogata H, Yoshioka T, Watanabe K, Nabekura Y and Tokuyama K: Case-study of blood glucose fluctuation and performance during $100 \mathrm{~km}$ marathon race. Tairyoku Kagaku 57: 285-294, 2008 (In Japanese).

7. Sengoku Y, Nakamura K, Ogata H, Nabekura Y, Nagasaka S and Tokuyama $\mathrm{K}$ : Continuous glucose monitoring during a $100-\mathrm{km}$ race: A case study in an elite ultramarathon runner. Int J Sports Physiol Perform 10: 124-127, 2015.
8. Romijn JA, Coyle EF, Sidossis LS, Gastaldelli A, Horowitz JF, Endert E and Wolfe RR: Regulation of endogenous fat and carbohydrate metabolism in relation to exercise intensity and duration. Am J Physiol 265: E380-E391, 1993.

9. Coggan AR, Kohrt WM, Spina RJ, Bier DM and Holloszy JO Endurance training decreases plasma glucose turnover and oxidation during moderate-intensity exercise in men. J Appl Physiol (1985) 68: 990-996, 1990.

10. Jansson E and Kaijser L: Substrate utilization and enzymes in skeletal muscle of extremely endurance-trained men. J Appl Physiol (1985) 62: 999-1005, 1987.

11. Japanese Ministry of Education, Culture, Sports, Science and Technology (MEXT): Food composition database. http://fooddb.jp/index.pl (accessed March, 2012).

12. Cooper KH: A means of assessing maximal oxygen intake. Correlation between field and treadmill testing. JAMA 203: 201-204, 1968.

13. Bidlingmeyer BA, Cohen SA and Tarvin TL: Rapid analysis of amino acids using pre-column derivatization. J Chromatogr 336: 93-104, 1984.

14. Iwai K, Hasegawa T, Taguchi Y, Morimatsu F, Sato K, Nakamura Y, Higashi A, Kido Y, Nakabo Y and Ohtsuki K: Identification of food-derived collagen peptides in human blood after oral ingestion of gelatin hydrolysates. J Agric Food Chem 53: 6531-6536, 2005.

15. Ezaki J, Matsumoto N, Takeda-Ezaki M,Komatsu M, Takahashi K, Hiraoka Y, Taka H, Fujimura T, Takehana K, Yoshida M, et al: Liver autophagy contributes to the maintenance of blood glucose and amino acid levels. Autophagy 7: 727-736, 2011. 